\title{
Reasons and patterns of hospitalization among schizophrenic patients in Greece: the Grace Study
}

\author{
Dimitra Karadima ${ }^{1 *}$, Ioannis Chatzimanolis ${ }^{2}$, Errikos Tsebelikos ${ }^{3}$, Venetsanos Mavreas ${ }^{4}$, Athanasios Fokas ${ }^{5}$, \\ Athanasios Kalogeropoulos ${ }^{6}$, Simeon Deres ${ }^{7}$, Theodosios Christodoulakis ${ }^{8}$ \\ From $1^{\text {st }}$ International Congress on Neurobiology and Clinical Psychopharmacology and European \\ Psychiatric Association Conference on Treatment Guidance \\ Thessaloniki, Greece. 19-22 November 2009
}

\section{Background}

Schizophrenia is one of the most frequent mental diseases with $1 \%$ probability among the whole population. Frequent hospitalization of schizophrenic patients is both a challenge to any health care system and a parameter that decreases patient quality of life and interrupts social functionality. The present analysis aims at assessing the current hospitalization pattern and at recording the most frequent reasons for hospitalization of schizophrenic patients in Greece.

\section{Materials and methods}

The Grace study was a descriptive, cross-sectional, multicentre national survey conducted in the outpatient setting by 104 psychiatrists proportionally distributed over Greece. Investigators registered one visit of each of the first 20 consecutive patients that presented at their consultation. Patient's demographics, living status, attending monitoring centre for schizophrenia, data on current treatment administration, number of hospitalizations and reasons of hospitalization were recorded. The analysis presented here involved only the subset of patients that were hospitalized during the last 12 months from the patient's visit to the doctor. Statistical analysis was performed by chi squared statistic, whereas magnitude of association is illustrated by odds ratios.

\section{Results}

The observational period lasted three months, from June 2007 to June 2008 and led to the recruitment of 2013 patients (mean age $39.7 \pm 12.5$ years old, $57.4 \%$ males

'Bristol-Myers Squibb, Greece and $42.6 \%$ females) with an ICD-10 primary diagnosis of schizophrenia. Out of the 2013 patients, 265 were hospitalized at least once during the past 12 months of the visit. The median number of prior hospitalizations was 3 , one of which occurred during the past 12 months and lasting up to 27 days for the $50 \%$ of patients. Besides the attending doctor, $66.92 \%$ of the patients were not monitored by any other medical centre. The reasons for hospitalization were: clinical deterioration (62\%), discontinuation of treatment (43\%), family burden $(17 \%)$, drug use $(10 \%)$, adverse events $(8 \%)$, suicide attempts $(8 \%)$ or other $(7 \%)$. Patients receiving aripiprazole were less likely to be hospitalized due to clinical deterioration $(\mathrm{OR}=0.68,95 \% \mathrm{CI}:[0.49-0.92], \mathrm{p}=0.019)$, treatment discontinuation $(\mathrm{OR}=0.77,95 \% \mathrm{CI}:[0.62-095]$, $\mathrm{p}=0.024)$ and family burden $(\mathrm{OR}=0.8995 \% \mathrm{CI}:[0.80-$ 0.99], $\mathrm{p}=0.026$ ), while patients receiving haloperidol were more likely to be hospitalized due to family burden $(\mathrm{OR}=1.18,95 \% \mathrm{CI}:[1.01-1.36], \mathrm{p}=0.013)$.

\section{Conclusions}

Clinical deterioration, discontinuation of treatment and family burden remain significant reasons of hospitalization in schizophrenic patients in Greece. Aripiprazol may lead to less frequent hospitalizations due to these reasons. Most schizophrenic patients in Greece are not monitored by other health care centers except form their attending doctor and future investigations are needed to investigate whether changes in these practice could lead to better management of the disease.

\footnotetext{
Author details

'Bristol-Myers Squibb, Greece. ²Department of Psychiatry, University Hospital "Eginition", Athens, Greece. ³epartment of Psychiatry, "Sismanogleion" Hospital, Athens, Greece. ${ }^{4}$ Department of Psychiatry, University Hospital,
} 
Ioannina, Greece. ${ }^{5}$ 2nd Department of Psychiatry, Hospital "Papageorgiou",

Thessaloniki, Greece. ${ }^{6}$ Hospital "Agia Fotini", Larissa, Greece. ${ }^{7}$ Hospital

"Therapeutirio Asklipios", Veria, Greece. " Hospital "Panagia Grigorousa",

Athens, Greece.

Published: 22 April 2010

doi:10.1186/1744-859X-9-S1-S95

Cite this article as: Karadima et al.: Reasons and patterns of

hospitalization among schizophrenic patients in Greece: the Grace

Study. Annals of General Psychiatry 2010 9(Suppl 1):S95.

Submit your next manuscript to BioMed Central and take full advantage of:

- Convenient online submission

- Thorough peer review

- No space constraints or color figure charges

- Immediate publication on acceptance

- Inclusion in PubMed, CAS, Scopus and Google Scholar

- Research which is freely available for redistribution

Submit your manuscript at 